\title{
UMA LEITURA CRITIICA DAS PESQUISAS SOBRE A RELAÇÃO ENTRE TRABALHO E EDUCAÇÃO
}

\author{
Anita Handfas*
}

\section{Resumo}

Analisam-se os pressupostos teóricos dos estudos sobre trabalho e educação que investigam essa temática do ponto de vista da teoria marxista. Numa leitura crítica das pesquisas que buscam estabelecer a relação entre trabalho e educação, muitos estudos têm o homem como categoria central de análise. Sobre essa constatação, Louis Althusser fala de um humanismo teórico. Ou seja, uma concepção que se refere à fase antropológica dos primeiros escritos de Marx, quando este ainda estaria influenciado por noções ideológicas. O artigo questiona se, do ponto de vista teórico e metodológico, proceder a determinadas análises tendo como base conceitual aquela desenvolvida pelo "jovem" Marx não estaria comprometendo a compreensão do próprio objeto de estudo. Nesse sentido, o argumento central é o de que a utilização dessa noção pode acarretar problemas de ordem teórica e metodológica para as análises que tratam da relação entre trabalho e educação.

Palavras-chave: Teoria. Trabalho. Educação.

\section{Introdução}

O objetivo deste texto é discutir, no plano da teoria, algumas questões concernentes à relação entre trabalho e educação. A questão fundamental que orienta o artigo é a de saber quais as implicações teórico-metodológicas do emprego da noção de homem nos estudos que tratam desta temática.

O problema a ser analisado pode ser enunciado da seguinte maneira: a assimilação equivocada da relação entre trabalho e educação nos estudos que buscam fazer a crítica às concepções da economia política burguesa da educação. Numa leitura das pesquisas que tratam das mudanças nas atuais

\footnotetext{
* Doutora em Educação pela Universidade Federal Fluminense, Brasil (2006). Professora Adjunta da Faculdade de Educação da Universidade Federal do Rio de Janeiro (ahandfas@bol.com.br).
} 
condições de produção e as suas consequências para a educação do trabalhador, verifiquei a ocorrência de elaborações que, fazendo uso do referencial teórico marxista, apontam para um desvínculo essencial entre a concepção burguesa de trabalho, que o reduz a uma mercadoria, e a concepção que vê no trabalho uma relação social fundamental que define o modo humano de existência.

Tais elaborações teóricas apoiam-se na noção de homem para a compreensão de todas as formas de sociabilidade na sociedade contemporânea. Nessa direção, a noção de trabalho surge como o elo de ligação entre o homem e a natureza, constituindo-se na própria essência humana. Como decorrência desse pressuposto, a questão central por onde passam as análises é identificada na ocorrência de um desajuste entre a essência humana e a sociedade capitalista.

De acordo com essa concepção teórica, a contradição entre trabalho e educação na sociedade capitalista se manifesta pela alienação do homem de sua própria essência, na medida em que o trabalho perde seu caráter emancipador. Nesse sentido, argumenta que a libertação do homem e a sua desalienação frente ao trabalho só seriam possíveis mediante a superação das relações sociais capitalistas de produção. Essas interpretações acabam por não apreender as determinações políticas, econômicas, sociais e ideológicas desses dois polos contraditórios.

A questão que se coloca, então, é a de compreender os motivos desses limites, já que, do ponto de vista teórico, essas interpretações empregam o marxismo como referencial analítico. Ou seja, sendo o marxismo, no meu entender, a teoria capaz de compreender cientificamente a realidade, como explicar o fato de que tais análises não estariam alcançando tal compreensão?

Encontrei em Louis Althusser uma importante contribuição teórica para ajudar a esclarecer tal paradoxo. Ele vai justificar a ocorrência de controvérsias no interior da teoria marxista por meio da distinção entre a problemática e a teoria. A problemática é o conjunto de questões ou as perguntas por onde a reflexão teórica encontra o caminho para se desenvolver. Sendo anterior à teoria, a problemática se refere ao lugar de onde as perguntas são formuladas, conduzindo, assim, o processo de reflexão teórica. Com base nessa distinção entre teoria e problemática é que podemos afirmar que teorias distintas podem pertencer a uma mesma problemática, desde que as questões ou as perguntas venham a ser formuladas de um mesmo lugar.

Essa formulação diz respeito à maneira como Althusser interpretou a teoria marxista. Para ele, a trajetória teórica de Marx teria sido marcada por uma ruptura entre a fase dos primeiros escritos de Marx, quando ele ainda estaria influenciado por noções ideológicas, e a fase de elaboração da ciência da história - do materialismo histórico. De acordo com esse pressuposto, ao 
formular a teoria da história, Marx teria substituído as velhas categorias filosóficas por conceitos inéditos na antiga concepção. Assim, Marx teria mudado de terreno na medida em que, onde antes falava de homem, de necessidade, de alienação, de roubo, de injustiça, de espírito, de liberdade, passou a falar de modo de produção, de forças produtivas, de relações de produção, de formação social, de infraestrutura, de superestrutura, de ideologias, de classes e de luta de classes.

Subjacente a essa proposição está a ideia de que as mudanças conceituais produzidas por Marx não são resultado somente de um amadurecimento teórico desse autor, em função de seu esforço individual e, portanto, isolado das circunstâncias históricas, políticas e sociais de seu tempo. Ao contrário, a compreensão de que a trajetória teórica de Marx foi marcada por uma ruptura faz alusão a uma tomada de posição teórica, e, sobretudo, política de Marx, ao se engajar nas lutas revolucionárias de seu tempo e se colocar do lado do proletariado. Nessa direção, a elaboração do materialismo histórico só foi possível a partir dessas condições e representou uma crítica radical à ideologia burguesa, transformando-se no principal instrumento teórico, político e ideológico a serviço da organização e da tomada do poder pelo proletariado ${ }^{1}$.

A partir dessas considerações, a hipótese que apresento para a discussão é a de que os limites na apreensão da dinâmica das mudanças nas condições de produção e a educação do trabalhador se devem justamente ao fato de os estudos críticos terem no homem a sua categoria central de análise. Nessa perspectiva, pretendo demonstrar que a recorrência sistemática da categoria de homem nesses estudos insere-se na problemática do humanismo teórico, que, na trajetória teórica de Marx, corresponderia a sua fase antropológica, a partir da qual se estruturaria o campo das noções de essência humana, alienação e emancipação humana, noções estas que estariam relacionadas aos primeiros escritos de Marx - 1843-1844 -, fase em que esse autor ainda estaria envolto na mesma problemática de Feuerbach.

Com efeito, trata-se de uma interpretação original sobre a trajetória teórica de Marx, que pode se constituir em um caminho fecundo para problematizar alguns elementos teóricos presentes nos estudos que tratam da relação entre trabalho e educação. Entretanto, vale ressaltar que a reflexão aqui apresentada não tem a pretensão de esgotar o debate, nem tampouco afirmar de modo

1. Longe de ser consensual, a questão da trajetória teórica de Marx é discutida e interpretada de diferentes maneiras no interior do marxismo. Para alguns autores, Marx nunca teria abandonado a problemática do humanismo, justamente por ser este inerente à própria essência da teoria marxista. Nesse sentido, esses autores reivindicam para a teoria marxista o humanismo, em contraposição ao humanismo burguês, de caráter ideológico e ahistórico. Não será objeto do presente artigo o aprofundamento desta questão. 
definitivo as concepções teóricas de Althusser a respeito de sua interpretação da teoria marxista. Ao propor o debate, me junto à compreensão de que, a despeito do que se pode supor, é possível encontrar diferentes concepções teóricas no interior do marxismo, entre as quais a distinção entre o materialismo histórico e o humanismo teórico, desenvolvidas por esse autor.

É importante esclarecer a acepção do conceito de humanismo teórico aqui empregada. Como sabemos, no plano da crítica política, podemos estabelecer uma distinção entre um humanismo de caráter conservador e um humanismo crítico. Entretanto, no plano da teoria, os limites se colocam quando essas ideologias humanistas passam a servir de referência básica para determinadas construções teóricas, daí a denominação de humanismo teórico.

A questão que se coloca, então, é a de saber que implicações o emprego de certas noções ancoradas no humanismo teórico podem trazer para as pesquisas do campo de estudos sobre trabalho e educação. Do ponto de vista teórico e metodológico, proceder a determinadas análises tendo como base conceitual aquela desenvolvida pelo jovem Marx não poderia comprometer a compreensão do próprio objeto de estudo?

Sem pretender aprofundar as questões aqui colocadas, o propósito deste trabalho é o de apresentar brevemente as duas problemáticas que teriam percorrido a trajetória teórica de Marx, para, nas conclusões, levantar algumas questões relativas à apreensão teórica e metodológica da relação entre trabalho e educação.

\section{0 humanismo teórico}

A tese althusseriana do humanismo teórico situa em Feuerbach o encontro de Marx com o homem. Como explicar um Estado que, a despeito de se julgar ser a razão e a liberdade, praticava a desrazão e o despotismo? Para a contradição razão-desrazão, Feuerbach apresentava a solução de uma teoria da alienação do homem. Nessa direção, ao invés da superação do idealismo hegeliano, Feuerbach limitou-se a inverter Hegel, abandonando a Ideia e colocando em seu lugar o Real Sensível, o Homem, o Concreto.

No período jovem de seus escritos, a alienação desempenhou um conceito chave na elaboração teórica de Marx. Em A Questão Judaica, Marx procurou analisar os fenômenos sociais à luz desse conceito, relacionando as condições materiais da sociedade com as condições espirituais e institucionais. Para Marx, a alienação era o resultado das relações entre a propriedade privada, o dinheiro e a mercadoria, por um lado, e a religião e o Estado, por outro, e, nesse sentido, a perda de sua essência devia-se, fundamentalmente, à submissão do homem aos interesses privados, que os dissociava dos interesses 
da comunidade. A necessidade da emancipação humana é colocada nos termos da perda de uma essência que necessitava ser recuperada.

Nos Manuscritos Econômicos e Filosóficos, a fundamentação da alienação parece ganhar um novo significado. A introdução da economia política fez intervir na análise da sociedade capitalista o conceito de trabalho alienado. Assim, a essência humana seria o trabalho, no sentido de auto-criação humana, que, segundo Marx, estaria alienado porque a alienação seria a submissão do trabalhador ao não trabalhador. Note-se que, não obstante a introdução de elementos da economia política, os Manuscritos é um texto que ainda está assentado numa concepção genérica do homem. A relação entre a alienação e a essência humana aparece quando Marx argumenta que o homem, ao se tornar individualista, se descola do gênero. A própria constatação de que o homem se aliena em relação ao gênero quando o não trabalhador subjuga o trabalhador, ainda que faça uma alusão às classes em conflito, permanece nos limites da ideia do altruísmo, da solidariedade e da harmonia entre o homem e a natureza. Assim, o trabalho alienado seria a expressão desajustada do trabalho como elemento da essência humana, uma vez que ele estabelece uma relação desarmônica entre os homens e entre estes e a natureza, produzindo uma sociedade não solidária, assentada no estranhamento do ser humano consigo mesmo e com os objetos que ele produz.

A ruptura de Marx com o humanismo teórico é identificada por Althusser a partir das Teses sobre Feuerbach e de A Ideologia Alemã, ambas escritas em 1845. Ao abandonar a teoria da essência do homem e se voltar à teoria da sociedade, Marx, de fato, avança definitivamente em direção do materialismo histórico, pois os objetos deixam de representar a objetivação da essência do homem para assumir uma dimensão que abarca as relações em todo o seu conjunto.

Assim, em A Ideologia Alemã o homem já não exerce mais o papel central, mas os indivíduos reais, vivendo em determinadas condições sociais e históricas. A ruptura que se processa com a concepção anterior de Marx tem consequências decisivas em sua obra, pois representa a sistematização de todo o sistema teórico sobre o qual se assentaram as bases da teoria da história - o materialismo histórico - e a filosofia marxista - o materialismo dialético.

De fato, é possível contrastar o pensamento de Marx em que predominava a concepção antropológica da história com o período em que ele elaborou a teoria da história. 


\section{0 materialismo histórico}

Em várias passagens de seus escritos, Marx e Engels deixaram claro o pressuposto fundamental de sua teoria: que toda formação social necessita produzir e reproduzir as condições de sua existência. Qualquer forma de produzir e reproduzir as condições de existência de uma determinada formação social implica um conjunto de processos de trabalho, cujo sistema constitui o processo de produção do modo de produção considerado. Em $O$ Capital, no capítulo que trata do processo de trabalho e do processo de produzir mais valia, Marx aponta o objeto de trabalho ou a matéria-prima extraída sob diversas formas da natureza, os instrumentos de produção e a força de trabalho como os elementos que intervêm em qualquer processo de trabalho e que, em conjunto, formam a unidade das forças produtivas. Esses três elementos formam a unidade dos processos de trabalho e se relacionam pela intervenção dos agentes que atuam sob o objeto de trabalho, empregando o instrumental de trabalho. O complexo dos objetos de trabalho e dos instrumentos de produção formam o que Marx chamou de meios de produção e se encontra à disposição dos homens em cada época histórica, indicando as condições sociais em que o processo de trabalho se realiza.

Para compreender a dinâmica interna desse complexo das forças produtivas que conforma os processos de trabalho é preciso considerá-lo como uma unidade contraditória que se expressa pelo efeito das relações sociais de produção existentes em cada formação social. As forças produtivas só podem ser postas em movimento sob relações sociais de produção, quer sob a forma de não cooperação, quer sob a forma de cooperação. Na formação social capitalista, onde coexistem classes antagônicas, os agentes da produção atuam sobre os objetos de trabalho por meio dos instrumentos de trabalho e em relações sociais de produção caracterizadas pela presença não só dos agentes de produção como também dos donos dos meios de produção, que, embora intervenham na produção, não participam dela diretamente. Vale ressaltar que as relações sociais de produção se apresentam de tal modo no capitalismo, a ponto de condicionar o uso dos meios de produção pelos agentes da produção ao controle do capitalista. Nas formações sociais capitalistas o controle do capitalista sobre os trabalhadores que põe em funcionamento os meios de produção é condição indispensável para que o trabalho seja social.

Essa forma de fazer intervir os elementos do processo de trabalho nas formações sociais capitalistas determina que as relações sociais de produção sejam relações de exploração, cujo mecanismo, explicitado por Marx, consiste no valor cedido pelo capitalista ao trabalhador, em troca da compra da utilização de sua força de trabalho, valor esse que representa o quantum necessário 
para a sua reprodução. A exploração da força de trabalho se dá no momento em que, no próprio processo de produção, o capitalista extrai um valor a mais daquele utilizado na compra da força de trabalho. Esse mecanismo encerra a principal característica do modo de produção capitalista, que é a de produzir a mais-valia e de produzir o próprio capital.

Se as relações sociais de produção capitalistas, que são relações de exploração, se dão no interior da produção através da extração da mais-valia, elas se manifestam também na maneira como se organizam todos aqueles que atuam nos processos de trabalho. A divisão do trabalho nas formações sociais capitalistas atinge um nível bastante elevado de complexidade, tendo em vista o próprio desenvolvimento das forças produtivas, e exige um aprimoramento crescente no que diz respeito à definição e à distribuição dos postos de trabalho necessários para a organização, a coordenação, a direção e a execução do processo de produção. Nas formações sociais capitalistas essa definição e essa distribuição se dão com base na divisão de classes existente na sociedade.

Se em qualquer formação social as forças produtivas, quando postas em movimento pelas relações de produção, são responsáveis pela produção das condições materiais dessas formações sociais, é certo que essa produção precisa ser reproduzida, sob pena de essas formações sociais desaparecerem. Ao reproduzir as condições de produção, cada formação social reproduz necessariamente as forças produtivas e as relações de produção. As reproduções dos meios de produção e da força de trabalho, que formam a unidade das forças produtivas, se realizam de maneiras distintas. Em O Capital, Marx mostrou o mecanismo global da reprodução ampliada das condições de produção na sociedade capitalista, estudando as relações de circulação do capital na produção dos meios de produção e na produção dos meios de consumo e a realização da mais-valia.

Diferentemente do processo de reprodução dos meios de produção, a reprodução da força de trabalho, no capitalismo, não se passa totalmente no interior da esfera produtiva. Por um lado, sua reprodução é feita por meio do salário, meio material de garantir a reposição da força de trabalho, já que ele representa a parte do valor produzida pelo seu desgaste e necessita ser reposta. Contudo, para reproduzir a força de trabalho no capitalismo, não basta garantir as condições materiais de sua reprodução. Para que a força de trabalho se reproduza para uma dada forma de produção, esta deve ser dotada de uma competência, de uma habilitação, possibilitando a sua utilização no sistema complexo do processo de produção, nos postos de trabalho e sob relações sociais de produção correspondentes. O desenvolvimento das forças produtivas e o tipo de unidade historicamente constituída das forças produtivas 
exigem que a força de trabalho seja habilitada para atender as exigências da divisão social do trabalho em seus diferentes postos. Esse é o motivo pelo qual a reprodução da qualificação da força de trabalho no capitalismo, diferentemente das formações sociais anteriores, não se dê na produção, mas fora dela, através do sistema escolar, segundo as exigências diversas colocadas pela divisão social do trabalho.

Tal qualificação pressupõe a aprendizagem dos códigos necessários para saber ler, escrever, contar, de modo a garantir o domínio dos elementos básicos da cultura científica, mas pressupõe também o aprendizado das regras de conduta necessárias e condizentes com o lugar definido pela divisão social do trabalho. Ou seja, a reprodução da força de trabalho se faz pela sua qualificação, qualificação essa em que está subtendida a sujeição ideológica do trabalhador ao capital.

Essa síntese do mecanismo de reprodução das forças produtivas faz intervir o mecanismo de reprodução das relações sociais de produção. Se toda formação social precisa produzir suas condições materiais, somente do ponto de vista da reprodução é possível compreender o mecanismo de funcionamento, assim como a articulação das diferentes instâncias presentes na totalidade orgânica que constitui um modo de produção.

Para Balibar (1980), que procurou sistematizar sua concepção marxista da teoria da história, formulando as suas proposições sobre a dinâmica interna do "todo social", deve-se pensar qualquer estrutura social como uma totalidade complexa, onde os diversos elementos que compõem essa totalidade se desenvolvem e se articulam de maneiras absolutamente desiguais. Essa dinâmica interna própria da totalidade complexa forma uma unidade contraditória entre seus elementos e implica necessariamente uma relação de dominação e subordinação entre eles, dependendo do lugar e da função que cada um desses elementos assume na estrutura social. Portanto, a existência da dominação e da subordinação entre os elementos do todo social é essencial à própria complexidade, sem o que uma estrutura deixaria de ser complexa, pois o modo como se desenvolvem e se articulam os elementos do todo complexo é que constitui a unidade contraditória. A estrutura do todo, a diferença das contradições ou as formas de articulação das contradições é a própria existência do todo. A totalidade só existe sob a condição de que em seu interior haja o movimento ou a dinâmica das contradições.

Essas considerações levaram Balibar (1980) a formular uma hipótese sobre a mudança histórica. Se uma estrutura não nasce de dentro da estrutura anterior, é preciso pensar a transição de um modo de produção para outro por meio de uma lógica distinta da reprodução desse modo de produção. Reprodução e transição são objetos que pertencem a teorias distintas. 
Do ponto de vista da reprodução, as contradições internas do todo social existem, mas permanecem circunscritas nos limites estruturais do modo de produção, e, apesar de não originarem um novo modo de produção, essas contradições fazem surgir elementos que não necessariamente se inserem no processo de reprodução, podendo vir a ser reorganizados numa nova estrutura social. Isso não é o mesmo que dizer que todas as coisas trazem dentro de si o princípio de sua própria destruição e, nessa direção, que o novo surgiria no decorrer do movimento, superando gradualmente o velho do qual nascera. Ao contrário da ideia hegeliana de conservação, é preciso pensar a reprodução como uma dinâmica que produz efeitos contraditórios em seu interior e faz surgir novos elementos da realidade que podem vir a ser articulados numa nova unidade em outro modo de produção.

Essa breve síntese de alguns elementos conceituais que constituem o materialismo histórico serviu para demarcá-lo do sistema conceitual por meio do qual se assentam os pressupostos do humanismo teórico.

\section{Pressupostos teóricos da relação entre trabalho e educação}

Tecendo algumas considerações a respeito do percurso do GT Trabalho e Educação da Anped, Trein e Picanço (1995) argumentam que esse campo de pesquisa "vem se construindo menos como um recorte no campo educacional e mais como a busca da elaboração teórico-metodológica que auxilie na compreensão da formação humana" (p. 89).

Isso significa que o próprio processo de constituição desse campo específico de pesquisa educacional resulta da definição dos pressupostos teóricos que conduziram as análises concernentes à relação entre trabalho e educação. Dizer que o campo se conformou na busca de uma elaboração teórica para compreender a formação humana já define de uma certa maneira a problemática sobre a qual a teoria foi assentada.

Um evento importante ilustra de forma clara essa questão. Trata-se da inversão da denominação do campo de estudos de 'Educação e Trabalho' para 'Trabalho e Educação'.

Tal inversão foi justificada por Kuenzer (1991, p. 92), ao mostrar que,

[...] a área estava padecendo de uma inversão ao tomar a educação como ponto de partida para a análise. Retomando-se os princípios fundamentais da crítica à economia política, concluiu-se que o que distingue esta área temática de outras no campo geral de educação é o fato de que nesta a dimensão trabalho constituiu-se como categoria central da qual se parte para a compreensão do fenômeno educativo e das articulações recíprocas entre estas duas dimensões - educação e trabalho. Reconhecer que o trabalho, na organização da sociedade, 
é o princípio educativo primeiro, é fundamental para superar a concepção burguesa da relação entre educação e trabalho, na qual a escola deverá articularse com o trabalho como estratégia de socialização e qualificação do trabalhador, tendo em vista as necessidades postas pelas relações capitalistas, com toda a sua dinamicidade.

Essa inversão marca o posicionamento teórico e metodológico assumido pelos estudiosos do campo, para quem o trabalho é o princípio educativo do homem. O homem se forma e se educa pelo trabalho, que adquire determinadas características de acordo com um modo de produção específico. Por ser seu elemento de formação, o trabalho é a própria essência do homem.

Tal inversão dos termos do campo de estudos de trabalho e educação teve o intento de criticar as concepções da economia política burguesa segundo as quais a educação era uma via para o crescimento individual e para o desenvolvimento econômico e social do país.

Nessa direção, para contrapor-se às concepções dos teóricos do capital humano, seus críticos tiveram como base o conceito de alienação. O problema central que conduziu a crítica estava na suposição de que a forma ahistórica da concepção burguesa de apresentar a realidade reduziria as noções de homem, trabalho e educação a uma esfera abstrata e desprovida de suas determinações históricas e sociais. Isso porque a sociedade capitalista provocaria a perda daquilo que representa o próprio substrato do devir humano, sua capacidade de produzir suas condições de existência e ao mesmo tempo produzir-se a si mesmo, capacidade essa que se configura em fundamento do conhecimento humano e em princípio educativo.

A não historicidade da análise burguesa da sociedade se manifestaria segundo seus críticos na forma indeterminada de se referir ao homem como se este fosse dotado de certas faculdades imutáveis, uma vez que essas seriam inerentes a sua própria natureza. Por esse caminho os teóricos do capital humano buscariam justificar a lógica do sistema de organização econômica do capitalismo baseada num mercado em concorrência perfeita. O que moveria o funcionamento da sociedade é a racionalidade e o egoísmo do homem. Assim, a troca e a divisão do trabalho, por exemplo, resultariam simplesmente do desejo das pessoas em satisfazerem suas necessidades.

Em contraposição, os críticos argumentavam que a concepção burguesa abstrata e ahistórica da sociedade ocultaria uma realidade muito mais complexa, que, para além de resultante de comportamentos individuais, seria determinada por relações sociais entre classes antagônicas. No capitalismo, essas relações seriam determinadas pela cisão entre os proprietários e os não proprietários dos meios de produção, condição essa que seria a causa da alienação do trabalhador, seja pelo fato de que ele deixa de se reconhecer nos 
produtos de seu trabalho, seja pelo fato de que a sua inserção no processo de produção se dá sob a degradação das suas condições materiais.

Com base nessas considerações foi desencadeado o processo de delimitação do marco teórico do GT Trabalho e Educação, que teve na noção de trabalho seu principal fundamento. Nesse sentido, a contradição encerra-se entre a noção burguesa de trabalho que, buscando naturalizar as relações sociais existentes no capitalismo, transforma-o em simples objeto, e a concepção segundo a qual o trabalho transcende a perspectiva pedagógica para constituir-se na própria essência do homem.

Sob essa ótica, o foco de análise é deslocado da relação em que a educação assume o papel de preparação para o mercado de trabalho para uma dimensão em que o trabalho é o elemento que caracteriza a própria existência humana, ou seja, o homem se educa em contato com a natureza por meio da aquisição do conhecimento e da consciência no processo de produção de sua existência.

A partir dessa premissa foi sistematizado todo o arcabouço conceitual de crítica às concepções ahistóricas da economia política burguesa. Nesse processo, buscou-se precisar o marco teórico tendo em vista a superação das dificuldades em articular os pressupostos teóricos anunciados à realidade concreta das investigações das temáticas que buscaram apreender sob diferentes enfoques a relação entre educação e trabalho.

No meu entender, essa tomada de posição teórica situa a problemática a partir da qual foi conformada uma nova concepção teórica que estabeleceu os vínculos entre trabalho e educação.

Antes de examinar algumas noções teóricas postas pelos estudos sobre trabalho e educação que advêm dessa problemática, é importante compreender os seus fundamentos.

Podemos situar essa problemática nos seguintes termos: como se sabe, em A Ideologia Alemã, Marx e Engels (1845) estabeleceram as premissas sobre as quais foi assentada a concepção materialista do mundo ao mostrarem que o ponto de partida são os homens vivos em constante relação com a natureza.

Marx e Engels (1845, p. 18) serviram-se dessa premissa para mostrar que o que distingue o homem dos animais é a sua capacidade de produzir os seus meios de existência.

Pode-se referir a consciência, a religião e tudo o que se quiser como distinção entre os homens e os animais; porém, esta distinção só começa a existir quando os homens iniciam a produção dos seus meios de vida, passo em frente que é consequência da sua organização corporal. Ao produzirem os seus meios de existência, os homens produzem indiretamente a sua própria vida material.

Vemos então que os dois pensadores fazem referência a imperativos que independem de quaisquer condições sociais. A necessidade de se vestir, de 
se alimentar e de se abrigar é uma necessidade supra-histórica. O que vai condicionar historicamente tais necessidades humanas são as relações sociais de produção travadas pelos homens em diferentes épocas históricas.

Portanto, me parece que é necessário perceber que entre as premissas ou antecedentes e os próprios fundamentos ou princípios do materialismo histórico há um ponto que constitui a chave de entendimento do processo histórico. Para compreendê-lo, Marx e Engels estudaram os diferentes estágios de desenvolvimento das forças produtivas, da divisão do trabalho e de suas respectivas formas de propriedade. Em outras palavras, o que constitui o materialismo histórico é o estudo das formas sociais (e não simplesmente biológicas) dos agrupamentos humanos em diferentes épocas históricas.

Com essas considerações, quero mostrar que a problemática sobre a qual os estudos do GT Trabalho e Educação foram conduzidos situou-se dentro dos limites das premissas da concepção materialista - o trabalho transforma o homem -, mas não avançaram em direção aos fundamentos do materialismo histórico - as formas históricas e sociais de produção e reprodução dos homens.

Podemos observar essa problemática por meio do emprego de algumas noções nas análises que relacionam trabalho e educação. É o que ocorre com a noção de trabalho que é tomada em sua acepção geral. Ou seja, na relação que se estabelece entre trabalho e educação, o trabalho adquire a primazia, na medida em que ele representa o fundamento do processo de elaboração do conhecimento. Isto porque o processo de produção do saber se dá no confronto do homem com a natureza e nas relações sociais travadas em cada época histórica.

Se retomarmos as considerações anteriores sobre as formas de manifestação do humanismo teórico, será possível verificar que a noção genérica de trabalho origina-se da relação especular estabelecida entre o homem e o objeto de seu trabalho e todos os efeitos de alienação resultantes dessa relação.

Uma observação a respeito do emprego genérico da noção de trabalho nos estudos que tem como temática a relação entre trabalho e educação foi feita por Tumolo (1997). Ele fez uma análise crítica da bibliográfia sobre o tema da "reestruturação produtiva no Brasil" e chamou a atenção para alguns problemas teóricos e metodológicos que impedem a apreensão do fenômeno em todas as suas determinações, identificando o limite dos estudos que trazem como referencial de análise o trabalho concreto, na medida em que abstraem o processo de trabalho de sua subordinação à lógica capitalista.

Podemos notar os obstáculos encontrados nas análises que empregam a ideia genérica e abstrata de trabalho quando verificamos a maneira pela qual Marx analisou a sociedade capitalista. A análise só foi possível em função do 
sistema conceitual por ele formulado. Nesse sentido, noções como trabalho só adquiriram sentido na medida em que foram empregadas como conceitos que permitiram compreender a realidade investigada. Assim, a noção de trabalho ganha força de conceito quando se articula à força de trabalho, trabalho concreto, trabalho abstrato, etc. No plano da análise social, isso corresponde a dizer que, para pensar a natureza do trabalho, Marx o fez pelas condições sociais de seu emprego.

Em sua análise do Programa do Partido Operário Alemão, Marx fez uso desse sistema conceitual. No que diz respeito ao enunciado de que "O trabalho é a fonte de toda a riqueza e de toda a cultura", Marx (1961, p. 211) afirmou que,

O trabalho não é a fonte de toda a riqueza. A natureza é a fonte dos valores de uso (que são os que verdadeiramente integram a riqueza material!), nem mais nem menos que o trabalho, que não é mais que a manifestação de uma força natural, da força de trabalho do homem. Essa frase encontra-se em todas as cartilhas e só é correta se se subtender que o trabalho é efetuado com os correspondentes objetos e instrumentos. Um programa socialista, porém, não deve permitir que tais tópicos burgueses silenciem aquelas condições sem as quais não têm nenhum sentido [grifo nosso].

A alusão aos meios de trabalho - objetos e instrumentos - e às condições em que o trabalho é realizado indica a maneira pela qual Marx fez intervir os conceitos, diferenciando-se da concepção burguesa que confere ao trabalho uma "força criadora sobrenatural".

O problema da sistematização conceitual na teoria marxista remete à questão da historicização das categorias assinalada por diversos autores como sendo a linha de demarcação do marxismo com relação a outras correntes teóricas. Uma das características centrais da teoria marxista, no que diz respeito ao seu método científico, é a sua capacidade de conduzir a investigação levando em conta as condições específicas de cada formação social. E aqui mais uma vez, é importante mencionar o sistema conceitual que compõe a teoria marxista, cujo emprego fornece as condições necessárias para a apreensão da realidade.

Nesse sentido, é preciso refletir também sobre o problema da historicização das categorias, supondo-se ser este um meio de afastar-se do geral para ir ao concreto da realidade investigada. A questão que se coloca é que, ao ser ignorada a função do sistema conceitual que forma a teoria marxista, podese acabar restringindo a historicização a uma contextualização histórica, no sentido de considerar os fatos históricos sem, contudo, compreendê-los em sua articulação com as demais instâncias da sociedade. 
O materialismo histórico implica muito mais do que uma contextualização histórica, ou do que uma relação do presente com o passado. Implica, sobretudo, levar em conta as formas de articulação sempre contraditórias dos elementos da realidade que se pretende investigar. A segunda questão a ser problematizada está relacionada à temática específica do presente trabalho. Entre as pesquisas que tratam das mudanças nas condições de produção e a educação do trabalhador, a politecnia é, sem dúvida, uma das questões que polemizam os estudiosos da área de trabalho e educação.

A ideia da politecnia está associada à superação da dicotomia entre trabalho manual e trabalho intelectual. Os estudiosos da área de trabalho e educação partem da suposição de que o sistema capitalista faz o homem perder a sua essência, na medida em que a intensificação da divisão social do trabalho fragmenta o processo de produção entre o trabalho manual e o trabalho intelectual. Nesse processo, o trabalhador se vê mutilado por perder a capacidade de domínio da totalidade do processo de trabalho.

Os estudiosos argumentam que numa sociedade baseada na socialização dos meios de produção o processo produtivo deve ser colocado a serviço de toda a sociedade, daí a suposição de que a divisão entre trabalho manual e trabalho intelectual seria superada, já que ambos formariam uma unidade indissolúvel em qualquer processo produtivo e sua separação teria sido condicionada pelo desenvolvimento do capitalismo. Trata-se, portanto, de adotar a politecnia como um instrumento que possibilite o domínio dos fundamentos científicos das diferentes técnicas que caracterizam o processo produtivo moderno.

Há questões aqui que devem ser discutidas.

No que concerne à educação escolar, a transmissão do acervo cultural e científico acumulado pela humanidade só poderá constituir-se de fato em uma unidade entre a teoria e a prática na sociedade socialista. Não obstante, é preciso notar que, se as sociedades socialistas devem perseguir a superação da divisão do trabalho e a conquista da unidade entre teoria e prática nos processos produtivos, elas também não poderão deixar de considerar o problema da especialização do trabalhador.

A ideia da combinação da politecnia com a necessidade de especialização profissional evita o equívoco de um discurso humanista genérico que tende para a ideia de um homem que faz tudo, ao mesmo tempo em que resgata a ideia do desenvolvimento multidimensional dos indivíduos.

No tocante às questões aqui discutidas, parece ser equivocado supor que no processo de desenvolvimento das forças produtivas na sociedade capitalista já se encontrariam os germes que assegurariam as condições necessárias para a superação da dicotomia entre trabalho manual e trabalho intelectual, 
assim como supor que na sociedade socialista a divisão do trabalho seria superada.

Os mesmos argumentos que justificam o fato de que os elementos cognitivos oferecidos aos filhos dos trabalhadores pela escola capitalista só poderão ser redimensionados na sociedade socialista, servem também para o fato de que a organização econômica e social da sociedade socialista deverá se calçar nas conquistas técnicas e científicas legadas pela humanidade, mas não poderá desconsiderar a divisão do trabalho na sociedade.

Ainda podemos tocar em mais um problema relacionado à ideia de politecnia Trata-se da questão da ciência e da tecnologia. O avanço tecnológico atingido na sociedade atual obedece a um padrão e a uma lógica próprias das sociedades capitalistas ${ }^{2}$. Isso significa que tanto o incremento da tecnologia quanto a sua utilização não gozam de nenhuma autonomia, mas estão subordinados às relações sociais que os determinam. Portanto, o avanço tecnológico por si só não poderá garantir o "reino da liberdade", ou a perda da condição da alienação humana; somente em uma sociedade sem antagonismos de classe é que a ciência e a tecnologia deverão adquirir um caráter de reconciliação do homem com a natureza.

Essa questão é tratada por diversos autores que analisam os impactos do avanço tecnológico na educação. Em muitos desses estudos, percebe-se uma ênfase nas forças produtivas, sem levar em conta as relações de produção que as comandam, numa compreensão de que o avanço do progresso técnico vem demandando uma elevação do patamar de qualificação.

No meu entender, esse equívoco se deve à análise unilateral da relação entre trabalho e educação. No caso da politecnia, o que se verifica é que a discussão fica limitada ao avanço das forças produtivas, desconsiderando-se as relações sociais de produção que no capitalismo são relações de exploração. Portanto, o que faz a classe trabalhadora se subjugar ao capital é o fato de que o capitalismo é um modo de produção que tem como objetivo primeiro não a produção dos objetos de utilidade social, mas a produção da mais-valia e a produção do capital. Ou seja, no modo de produção capitalista, a produção dos objetos de utilidade social é inteiramente subordinada à produção da mais-valia, isto é, à produção ampliada do capital. A própria produção está subordinada à exploração e, portanto, à produção ampliada do capital.

Sob essas condições e não pelo fato de o trabalhador se alienar dos produtos de seu trabalho é que a classe burguesa pode exercer seu domínio político e ideológico sobre a classe trabalhadora.

2. Em um artigo em que discute a questão da tecnologia no socialismo, Wallis (2006) nos leva a questionar a própria viabilidade do avanço tecnológico nas sociedades capitalistas, na medida em que esse avanço estaria subordinado a uma racionalidade própria do capitalismo. 


\section{Considerações finais}

O objetivo deste artigo foi o de analisar criticamente os estudos que buscam estabelecer a relação entre trabalho e educação. Para tal, busquei resgatar a tese de Louis Althusser acerca de sua interpretação da trajetória teórica de Marx, mais especificamente, a distinção entre a fase denominada por Althusser de humanismo teórico e a fase em que Marx estaria operando com o arcabouço teórico e conceitual do materialismo histórico.

As questões teóricas que foram apresentadas para debate tiveram origem na constatação de que as investigações concernentes ao campo de estudos de trabalho e educação estão assentadas de forma recorrente, e não necessariamente exclusiva, no humanismo teórico.

Vários fatores me levaram a essa constatação. O primeiro deles diz respeito à maneira pela qual os estudos formularam a crítica à economia política da educação. Identificando nos teóricos do capital humano a afirmação de uma suposta essência humana egoísta e proprietária como forma de justificar a ascensão social por meio do esforço individual, a crítica a essa concepção se deu fundamentalmente pela afirmação de que a essência humana é histórica, na medida em que ela estaria condicionada pelos fatores culturais, sociais, econômicos e políticos presentes em cada período histórico.

Nos estudos que tratam da relação entre trabalho e educação, essa suposição está relacionada à ideia de que na sociedade capitalista o homem aliena a sua essência nos produtos do trabalho, quer pelo fato de ser obrigado a vender a sua força de trabalho, quer pelo fato de que o sistema capitalista tende a acelerar cada vez mais a divisão do trabalho.

O que parece ser especialmente problemático é que entre esses referenciais explicativos e críticos e a realidade concreta e objetiva do capitalismo há que se situar necessariamente o conhecimento histórico desse modo de produção, e não o desvendamento do capitalismo em si, como parece ser o sentido da crítica, uma vez que ela se pauta em noções genéricas do homem, da perda de sua essência, de seus interesses contrariados, ao invés de analisar o capitalismo tendo em vista as suas condições sociais, dos processos de trabalho, do processo de valorização e de suas formas ideológicas.

A relação entre as mudanças nas condições de produção e a educação do trabalhador tem sido objeto de inúmeros trabalhos da área de trabalho e educação que vêm estudando esse problema. Mas na sua grande maioria, esses estudos examinam as consequências sociais da chamada reestruturação produtiva, ou seja, trata-se então de analisar as vantagens e os inconvenientes desse fenômeno com o objetivo de identificar os novos padrões de qualificação do trabalhador. 
Nesses estudos, as mudanças nos processos produtivos são consideradas dominantemente como progresso das forças produtivas, ou, para empregar os termos correntes nesses estudos, como progresso técnico. Essa é uma consequência do fato de que o estudo dos aspectos sociais das condições capitalistas de produção é reduzido à questão do desenvolvimento das forças produtivas, sem articular esse elemento às relações de produção que as mantêm.

Sem negar que essas análises produzam efetivamente conhecimentos sobre a relação entre trabalho e educação em geral e as mudanças nos processos produtivos e a educação do trabalhador em particular, é necessário notar que, tal como é empregada em um grande número de estudos, a noção de mudanças nos processos produtivos acaba por esconder o verdadeiro conteúdo desse processo, fazendo-o passar por um processo de desenvolvimento neutro das forças produtivas.

Por esse motivo, é necessário considerar as atuais condições capitalistas de produção como um processo social, e mais precisamente como uma forma do desenvolvimento das forças produtivas adequadas a relações de produção determinadas, no caso, as relações de produção capitalistas. O que equivale a dizer que o desenvolvimento das forças produtivas toma as formas adaptadas à reprodução das relações de produção dominantes.

Essa questão interessa particularmente aos estudos da área de trabalho e educação. Como foi assinalado, a politecnia tem se constituído em uma das questões centrais que vem ocupando o debate entre os estudiosos da área de trabalho e educação. A esse respeito, procurei argumentar que, como os estudos que tive acesso tendem a analisar unilateralmente essa questão, com foco prioritário no avanço das forças produtivas, a politecnia surge como uma consequência desse processo.

O equívoco aqui pode estar ocorrendo porque essas análises desconsideram o fato de que o avanço das forças produtivas, que no limite expressam o progresso técnico e científico alcançado pela humanidade, intensifica a divisão social do trabalho, impondo, sob formas diferenciadas, a necessidade da especialização do trabalhador.

Dessa forma, no que concerne ao debate em torno da questão da politecnia, o humanismo teórico se faz aí presente na medida em que a problemática que dirige as reflexões dos estudiosos se assenta na ideia de um homem que, graças ao intenso progresso técnico e científico colocado a sua disposição, já estaria em condições de se reconciliar com a sua própria essência.

Este artigo não teve a intenção de ser propositivo, mas somente de acrescentar novos elementos para a análise da relação entre trabalho e educação. Entretanto, a título de uma breve sistematização, penso que é importante 
levantar alguns pontos que devem ser considerados nos estudos sobre as mudanças nas condições de produção e suas consequências na educação do trabalhador.

Como pensar a relação entre as mudanças nas condições capitalistas de produção e a educação do trabalhador?

Sem a pretensão de aprofundamento e de forma breve, elenco os seguintes pontos:

Considerar que as mudanças nas condições de produção no interior do modo de produção capitalista têm que ser analisadas enquanto contradições internas que se mantêm nos limites estruturais do modo de produção. Essa questão é muito importante, pois faz pensar nas análises que entendem tais mudanças como um desenvolvimento contínuo e linear das forças produtivas.

A escola capitalista e a produção capitalista geram um trabalhador qualificado. Trata-se de analisar as contradições decorrentes desse processo, de modo a apreender o tipo de qualificação, assim como definir as condições materiais e ideológicas que engendram, na escola e na produção, esse tipo de qualificação.

É necessário também analisar essa unidade tendo em vista as classes sociais que a compõem, assim como as práticas sociais dos agentes presentes na escola e na produção.

\section{Referências}

ALTHUSSER, Louis. Sobre o jovem Marx (Questões de Teoria). In: . Análise crítica da teoria marxista. Rio de Janeiro: Zahar, 1967. p. 39-74. 1999. . A querela do humanismo. Crítica Marxista, São Paulo: Xamã, n. 9, p. 9-51,

. A querela do humanismo (II). Crítica Marxista, São Paulo: Boitempo Editorial, n. 14, p. 48-72, 2002.

BALIBAR, Étienne. Sobre os conceitos fundamentais do materialismo histórico. In: ALTHUSSER, Louis; BALIBAR, Étienne; ESTABLET, Roger. Ler O Capital, vol. 2. Rio de Janeiro: Zahar, 1980. p. 153-274.

KUENZER, Acacia Zeneida. Educação e trabalho no Brasil: o estado da questão. Brasília: Inep; Santiago: Reduc, 1991.

MARX, Karl. Crítica ao Programa de Gotha. In: MARX, Karl; ENGELS, Friedrich. Obras escolhidas. vol. 2. Rio de Janeiro: Editorial Vitoria, 1961. p. 205-236.

. Manuscritos econômicos e filosóficos. São Paulo: Boitempo Editorial, 2004.

1968.

. O Capital. Livro primeiro, volume I. Rio de Janeiro: Civilização Brasileira, . A questão judaica. Rio de Janeiro: Achiamé, s/d. 
MARX, Karl; ENGELES, Friedrich. Teses sobre Feuerbach [1845]. In: MARX, Karl; ENGELES, Friedrich. A ideologia alemã. Portugal: Editorial Presença, Brasil: Livraria Martins Fontes, vol. 1, 3. ed., s/d. p. 11-102.

MARX, Karl; ENGELS, Friedrich. A ideologia alemã [1845]. 3. ed. Portugal: Editorial Presença, Brasil: Livraria Martins Fontes, vol. 1, s/d.

TREIN, Eunice S.; PICANÇO, Iracy S. O GT Trabalho e Educação. Anped. Histórico dos Grupos de Trabalho. Anped, p. 87-90, set. 1995.

TUMOLO, Paulo Sergio. Metamorfose no mundo do trabalho: revisão de algumas linhas de análise. Educação e Sociedade. Campinas: Cedes, Unicamp, n. 59, p. 333-350, ago. 1997.

WALLIS, Victor. Socialismo e tecnologia: uma visão setorial. Crítica Marxista, Rio de Janeiro: Revan, n. 22, p. 55-74, 2006. 


\section{A critical reading of the researches on the relation between work and education Abstract}

The theoretical foundations of the studies on work and education which investigate this theme from a Marxist point of view are analyzed. Based on critical reading of the researches that try to establish a relation between work and education, several studies take man as a main category of analysis, This fact brings Althusser to speak of theoretical humanism. In other words, a conception which refers itself to the anthropological phase of the first writings of Marx, when he was still influenced by ideological notions. The article questions whether, from a theoretical and methodological point of view, to proceed with certain analyses conceptually based on that developed by the "young" Marx would not compromise the comprehension of the relation between work and education.

Keywords: Theory. Work. Education.

\section{Une lecture critique des recherches sur la relation entre travail et éducation Résumé}

L'embasement théorique des études sur le travail et éducation qui investiguent cette thématique du point de vue de la théorie marxiste est analysé. À partir d'une lecture critique des recherches qui tentent établir une relation entre travail et éducation, plusieurs études utilisent homme comme catégorie centrale d'analyse. Devant cette constatation, Althusser fait mention d'un humanisme théorique. Ou cela disant, une conception que se réfère à la phase anthropologique des premiers écrits de Marx, quand celui-ci était encore influencé par les notions idéologiques. Cet article questionne si, du point de vue théorique ou méthodologique, procéder à de telles analyses ayant comme base conceptuelle celle développée par le « jeune »Marx ne compromettrait pas la compréhension de la relation entre travail et éducation.

Mots clefs : Théorie. Travail. Éducation.

\section{Una lectura crítica de las pesquisas sobre la relación entre trabajo y educación Resumen}

Se analizan los presupuestos teóricos de los estudios sobre trabajo y educación que investigan esa temática del punto de vista de la teoría marxista. En una lectura crítica de las pesquisas que buscan establecer la relación entre trabajo y educación, muchos estudios tienen el hombre como categoría central de análisis. Sobre esa constatación, Louis Althusser habla de un humanismo teórico. O sea, una concepción que se refiere a la fase antropológica de los primeros escritos de Marx, cuando él aún estaría, influenciado por nociones ideológicas. El artículo cuestiona si, del punto de vista teórico y metodológico, proceder a determinados análisis teniendo como base conceptual aquella desarrollada por el "joven" Marx no estaría comprometiendo la comprensión de la relación entre trabajo y educación.

Palabras clave: Teoría. Trabajo. Educación.

Recebida 1a versão em: 14.06.2009

Aceita 2a versão em: 26.07.2010 